\title{
Working memory- and anxiety-related behavioral effects of repeated nicotine as a stressor: the role of cannabinoid receptors
}

Tamaki Hayase

\begin{abstract}
Background: Like emotional symptoms such as anxiety, modulations in working memory are among the frequently-reported but controversial psychiatric symptoms associated with nicotine (NC) administration. In the present study, repeated NC-induced modulations in working memory, along with concurrently-observed anxietyrelated behavioral alterations, were investigated in mice, and compared with the effects of a typical cognitionimpairing stressor, immobilization stress (IM). Furthermore, considering the structural and functional contributions of brain cannabinoid (CB) receptors in NC-induced psychiatric symptoms including emotional symptoms, the interactive effects of brain CB receptor ligands (CB ligands) and NC and/or IM on the working memory-and anxiety-related behaviors were examined.

Results: Statistically significant working memory impairment-like behavioral alterations in the Y-maze test and anxiety-like behavioral alterations in the elevated plus-maze (EPM) test were observed in the groups of mice treated with $0.8 \mathrm{mg} / \mathrm{kg} \mathrm{NC}$ (subcutaneous (s.c.) $0.8 \mathrm{mg} / \mathrm{kg}$ treatment, 4 days) and/or IM (10 min treatment, 4 days). In the group of mice treated with NC plus IM (NC-IM group), an enhancement of the behavioral alterations was observed. Among the CB type 1 (CB1) antagonist AM 251 (AM), the non-selective CB agonist CP 55,940 (CP), and the CB1 partial agonist/antagonist virodhamine (VD), significant recovering effects were provided by AM $(0.2-2.5 \mathrm{mg} / \mathrm{kg})$ and VD $(5 \mathrm{mg} / \mathrm{kg})$ against the working memory impairment-like behaviors, whereas significant anxiolytic-like effects (recoveries from both attenuated percentage of entries into open arms and attenuated percentage of time spent on open arms) were provided by VD (1-10 mg/kg) and CP (2 mg/kg) against the anxiety-like behaviors.

Conclusions: Although working memory impairment- and anxiety-like behavioral alterations were commonly induced in the NC, IM, and NC-IM groups and the therapeutic involvement of CB receptors was shown, there were discrepancies in the types of effective CB ligands between the working memory- and anxiety-related behaviors. The differential involvements of CB receptor subtypes and indirectly activated neurotransmitter systems may contribute to these discrepancies.
\end{abstract}

Keywords: Nicotine, Immobilization stress, Working memory, Anxiety, Cannabinoid, AM 251, CP 55,940, virodhamine

Correspondence: thayase@mri.biglobe.ne.jp

Department of Legal Medicine, Kyoto University, Yoshidakonoe-cho,

Sakyo-ku, Kyoto 606-8501, Japan 


\section{Background}

Nicotine (NC) is the substance which sustains the addictive use of tobacco, and tobacco results in numerous harmful health effects and continues to be the leading cause of preventable death [1,2]. It has been reported that addicted tobacco users suffer from NC-induced cognitive impairments in some conditions of smoking, as well as modulated moods such as anxiety- and depression-related symptoms [3-5]. Cognitive impairments including deficits in working memory, a process for maintaining temporary active information [6], have been regarded as being among the representative symptoms of $\mathrm{NC}$ withdrawal observed in NC-dependent human and rodent models $[3,7,8]$. Furthermore, the direct neurotoxic effects of $\mathrm{NC}$ have also been reported depending on the treatment conditions such as dose, period and paradigm, and this neurotoxicity has been suggested to induce memory impairments, particularly at earlier periods in development [9-12]. However, in some clinical and experimental animal studies, cognitive improvements or absence of any effects have been demonstrated [13-17]. Negative, positive or no effects of $\mathrm{NC}$ have also been reported against the anxiety-related behaviors [18-20].

Working memory impairments have been reported for various stressors such as restraint stress (immobilization stress) in both humans and rodent models [21-23]. Like certain NC treatments, such stressors also induce and exacerbate the anxiety-like behavioral responses in rodent models [24,25]. Furthermore, it has been suggested that brain regions such as the medial prefrontal cortex, for which $\mathrm{NC}$-induced modulations have been demonstrated [26,27], are concurrently involved in the development of stress-induced working memory impairments and anxiety [28-31]. However, there are only a few studies investigating the characteristic effects of NC as a stressor, particularly those on cognitive function [32,33].

A considerable number of studies have implicated the relationship between $\mathrm{NC}$ and stress. For example, in some rodent models, repeated or acute stress has been shown to aggravate the behavioral and neuronal effects of NC [34-36]. Recent human studies have shown some directly-exacerbated mood symptoms induced by stress in smokers $[37,38]$. However, against the behavioral and neuronal impairments caused by stress, antagonistic effects of subsequently administered NC have been shown in some rodent models [39-41]. With respect to cognitive function, $\mathrm{NC}$ has also been reported to block stress-induced impairments in several experimental conditions in rodents $[41,42]$. Nevertheless, the abovementioned neurotoxic effects of $\mathrm{NC}$ which could lead to cognitive dysfunction [10-12] may be correlated with the possibility that NC and stress augment each other's unfavorable effects on cognitive function.
In previous studies, a strong involvement of brain cannabinoid (CB) receptors, typically $\mathrm{CB}$ type 1 (CB1) receptors, was reported in the representative emotionrelated behaviors (anxiety- and depression-like behaviors) induced by $\mathrm{NC}[18,43,44]$ and stress $[45]$ in rodents. This is consistent with the prominent behavioral alterations induced by $\mathrm{NC}$ in $\mathrm{CB} 1$ knockout mice [46], and the overlapping distribution of $\mathrm{CB} 1$ receptors and nicotinic acetylcholine receptors ( $\mathrm{nAChRs)}$ in some brain regions which supports functional interactions between these receptors $[47,48]$. Furthermore, recent reviews suggest that CB1 receptors contribute to deficits in memory including working memory by demonstrating that CB1 agonists impair memory formation and $\mathrm{CB} 1$ antagonists reverse these impairments $[49,50]$. However, there have been a limited number of studies on the direct contribution of brain $\mathrm{CB}$ receptors to the memory-related effects of $\mathrm{NC}[51,52]$. The participation of $\mathrm{CB1}$ receptors has also been reported in anxiety processes, but the roles of CB1 agonist are contradictory in that both anxiolytic-like and anxiogenic-like effects have been induced depending on the treatment conditions [53,54]. Against the NC-induced anxiety-related behaviors, inconsistent and contradictory effects of CB1 agonists and other CB ligands have also been demonstrated $[18,43]$.

In the present study, using behavioral tests in mice ( $\mathrm{Y}$ maze and elevated plus-maze (EPM) test), the working memory- and anxiety-related behavioral alterations caused by $\mathrm{NC}$ were assessed and compared with those caused by immobilization stress (IM), a typical stressor. The interactions between the NC- and IM-induced behavioral effects were also examined. Furthermore, considering the possible involvement of brain $\mathrm{CB}$ receptors in these NC- and/or IM-induced memory- and anxiety-related behavioral alterations, the effects of selected CB ligands (the CB1 antagonist AM 251, the non-selective CB agonist CP 55,940, and the CB1 partial agonist/antagonist virodhamine) were evaluated against these behavioral alterations, as described in previous studies $[43,51,52]$.

\section{Methods}

\section{Animals}

Based on previous studies on $\mathrm{NC}$ and stressor treatments [43,55], male ICR mice $(80 \pm 10$ days old $)$ (Shizuoka Laboratory Animal Center, Hamamatsu, Japan) were housed in a forced-air facility, which was maintained at $23^{\circ} \mathrm{C}$ and $50 \%$ relative humidity, with a 12 $\mathrm{h} / 12 \mathrm{~h}$ light/dark cycle. The mice were kept separately in single transparent cages measuring $23.5 \times 16.5 \times 12$ $\mathrm{cm}$, and were allowed water and rodent chow ad libitum. The experiments described in this report were conducted in accordance with the "Guidelines for Animal Experiments" of the institution (updated in 
2007) [56], which are based on the National Institutes of Health Guide for the Care and Use of Laboratory Animals, and any pain experienced by the mice was minimized. These guidelines were approved by the institutional ethics committee for animal experiments [56]. All of the observations and evaluations were performed by a trained observer who was blinded to the treatment conditions and was not informed of the treatment conditions in advance. Each experimental group contained 10 mice.

\section{Drug and stressor treatments}

The protocols for the NC and stressor treatments were determined based on preliminary experiments and previous studies [43,55,57]. With respect to $\mathrm{NC}$, repeated subcutaneous (s.c.) doses of NC which caused the emotional behaviors (anxiety- and depression-like behaviors) effectively in mice [43] were selected: single s.c. doses of 0.3 or $0.8 \mathrm{mg} / \mathrm{kg}$ were administered daily for 4 days. NC (Nacalai Tesque, Inc., Kyoto, Japan) was supplied in free-base form at $95 \%$ purity, and was freshly dissolved in saline to a volume of $5 \mathrm{ml} / \mathrm{kg}$ immediately before each administration. With respect to the stressor, treatments using IM, which have also been demonstrated to cause these emotional behaviors in rodents $[44,58]$, were used. In the present experiments, repeated IM treatments in which the effects were almost equivalent to the peak effects of the NC treatments in preliminary experiments were selected: $10 \mathrm{~min}$ of IM, which was induced by placing the mouse in a narrow space (diameter about 12 $\mathrm{cm}$ ) in a vinyl bag with some breathing holes, was performed once per day for 4 days. Furthermore, to investigate the interactions between $\mathrm{NC}$ and IM, the behavioral alterations were examined in the NC plus IM group (NC-IM group) which received the above s.c. dose of NC 10 min before the IM treatment once per day for 4 days, according to a previous study [59].

The CB ligands AM 251 (N-(piperidin-1-yl)-5-(4iodophenyl)-1-(2,4-dichlorophenyl)-4-methyl-1H-pyrazole3-carboxamide) (AM), CP 55,940 ((-)-cis-3-[2-hydroxy4-(1,1-dimethylheptyl)phenyl]-trans-4-(3-hydroxypropyl) cyclohexanol) (CP), and virodhamine (O-(2-aminoethyl)5Z,8Z,11Z,14Z-eicosatetraenoate) (VD) were purchased from Tocris Cookson Inc. (Ellisville, Missouri, USA), and the doses were selected based on previous studies and preliminary experiments $[43,51,52]$. For each drug, the data were collected and shown for those intraperitoneal (i.p.) doses which induced no toxic behavioral alterations by themselves at the prescribed time point: $0.2,1$ and $2.5 \mathrm{mg} / \mathrm{kg}$ for AM, $0.5,2$ and $5 \mathrm{mg} / \mathrm{kg}$ for $\mathrm{CP}$, and 1,5 and $10 \mathrm{mg} / \mathrm{kg}$ for VD. The CB ligands were dissolved and diluted using a mixed solution of dimethylsulphoxide (DMSO) plus distilled water, and were administered in a volume of $5 \mathrm{ml} / \mathrm{kg}$, $60 \mathrm{~min}$ before each NC, IM or NC-
IM treatment, considering the previously examined time course of the effects of $\mathrm{CB}$ ligands against the NC- and/ or IM-induced working memory- and anxiety-related behaviors $[43,58]$. Since VD was provided in an ethanol solution (Tocris Cookson Inc.), the ethanol was evaporated immediately before use under nitrogen gas, and the residue was re-suspended in the same mixed DMSO/distilled water solution. In the NC- and IM-only groups, a mixed vehicle solution of DMSO and distilled water at the same ratio as the $\mathrm{CB}$ ligand solutions was injected instead of the $\mathrm{CB}$ ligands. In the $\mathrm{CB}$ ligand-only groups, the same volume of saline vehicle was injected instead of the NC or IM treatment. In the control group without any drug or stressor treatment (control group), the mixed vehicle solution of DMSO and distilled water was injected instead of the $\mathrm{CB}$ ligands, and then the same volume of saline vehicle was injected instead of the NC or IM treatment. The drug and stressor treatments and each experimental session were performed between 15 and $19 \mathrm{~h}$ of the light cycle.

\section{Y-maze test}

Based on previous studies $[28,60,61]$, alterations in working memory-related behaviors were examined in the Y-maze test using a cardboard apparatus that consisted of three enclosed arms $30 \times 5 \times 15 \mathrm{~cm}$ (length, width, and height) which converged on an equilateral triangular center platform $(5 \times 5 \times 5 \mathrm{~cm})$. After the number of spontaneous alteration performance (SAP), which was defined as the number of successive triplet entry performances into each of the three arms without any repeated entries $[28,60,61]$, and the total number of entries into arms were evaluated (8 min test periods), the rate of spontaneous alteration performance (SAP rate) (\%) was calculated as a parameter for the working memory-related behaviors. The total number of entries into arms was assessed as a parameter representing locomotor activity [60,61]. Considering the previous data [58], the evaluations of these parameters were performed at the $2 \mathrm{~h}$ time point after the last NC, IM or NC-IM treatment. At the beginning of each experimental session, each mouse was placed in the center platform of the maze, facing all three arms immediately before the session [58].

\section{Elevated plus-maze (EPM) test}

Based on previous studies [18,43,62-64], alterations in anxiety-related behaviors were examined in the EPM test using a cardboard apparatus that consisted of two opposite open arms $50 \times 10 \mathrm{~cm}$ (length and width) and two enclosed arms $50 \times 10 \times 30 \mathrm{~cm}$ (length, width, and height), positioned $50 \mathrm{~cm}$ from the floor. After the number of entries into open arms, the time spent on open arms (sec), and the total number of entries into arms were evaluated ( $5 \mathrm{~min}$ test periods), the percentage of 
entries into open arms and the percentage of time spent on open arms were calculated as parameters for the anxiety-related behaviors. The total number of entries into arms was assessed as a parameter representing locomotor activity [63]. Considering the previous data [43], the evaluations of these parameters were performed at the $2 \mathrm{~h}$ time point after the last NC, IM or NC-IM treatment. At the beginning of each experimental session, each mouse was placed diagonally in the center platform of the maze, facing both the open and enclosed arms [43].

\section{Statistical analysis}

The data were subjected to two-way analysis of variance (ANOVA) for both effects of NC and/or IM and effects of the CB ligands [65]. With respect to the experiments examining the effects of $\mathrm{NC}$ and/or IM, a $3(0.3 \mathrm{mg} / \mathrm{kg}$ $\mathrm{NC}, 0.8 \mathrm{mg} / \mathrm{kg} \mathrm{NC}$ versus vehicle) $\times 2$ (IM versus vehicle) factorial design was used for the factors $\mathrm{NC} \times \mathrm{IM}$ treatment. With respect to the experiments examining the effects of the CB ligands, a 4 (NC, IM, NC-IM versus vehicle) $\times 4$ (three doses of each $\mathrm{CB}$ ligand versus vehicle) factorial design was used for the factors $\mathrm{NC}$ and/ or IM treatment $\times$ treatment using each CB ligand. For pairwise comparisons, Bonferroni post-hoc tests were performed [65]. All of the comparisons were performed using a statistical software package ("Excel Statistics" from Social Survey Research Information Co. Ltd. Inc., Tokyo, Japan). P values less than 0.05 were considered to be statistically significant.

\section{Results}

NC- and/or IM-induced working memory-related behavioral alterations in the $\mathrm{Y}$-maze test

In the $0.8 \mathrm{mg} / \mathrm{kg} \mathrm{NC}, \mathrm{IM}$ and NC-IM groups, at the $2 \mathrm{~h}$ time point, behavioral alterations indicating working memory impairments, i.e. statistically significantly attenuated SAP rates (Figure 1), in spite of the absence of significant changes in the total numbers of entries into arms (Table 1), were observed in the Y-maze test. This is consistent with the results of the ANOVA revealing statistically significant main effects of $\mathrm{NC}(\mathrm{F}(2,54)=11.02, \mathrm{P}<0.001)$ and $\mathrm{IM}(\mathrm{F}(1$,
Table 1 Total number of entries into arms in experiments examining the effects of NC and/or IM (experiments shown in Figures 1 and 2)

\begin{tabular}{ccc}
\hline & Y-maze test (Figure 1) & EPM test (Figure 2) \\
\hline Control group & $47.1 \pm 8.3$ & $63.2 \pm 12.4$ \\
NC 0.3 group & $51.2 \pm 8.4$ & $59.1 \pm 12.3$ \\
NC 0.8 group & $43.7 \pm 8.5$ & $58.5 \pm 11.9$ \\
IM group & $44.5 \pm 8.2$ & $60.8 \pm 12.1$ \\
NC 0.3-IM group & $49.0 \pm 8.6$ & $56.5 \pm 12.0$ \\
NC 0.8-IM group & $43.2 \pm 8.6$ & $55.0 \pm 11.7$ \\
\hline
\end{tabular}

$54)=34.03, \mathrm{P}<0.001)$. For the NC-IM groups, the SAP rates were significantly attenuated as compared to the $\mathrm{NC}$ and/ or IM groups.

\section{NC- and/or IM-induced anxiety-related behavioral alterations in the EPM test}

In the NC, IM and NC-IM groups, at the $2 \mathrm{~h}$ time point, anxiety-like behavioral alterations, i.e. statistically significantly attenuated percentage of entries into open arms (Figure 2a) and significantly attenuated percentage of time spent on open arms (Figure 2b), in spite of the absence of significant changes in the total numbers of entries into arms (Table 1), were observed in the EPM test. This is consistent with the results of the ANOVA revealing statistically significant main effects of $\mathrm{NC}(\mathrm{F}(2,54)=195.21$, $\mathrm{P}<0.001$ for the percentage of entries into open arms and $F(2,54)=70.18, P<0.001$ for the percentage of time spent on open arms) and IM $(F(1,54)=104.38, \mathrm{P}<0.001$ for the percentage of entries into open arms and $F(1$, $54)=46.89, \mathrm{P}<0.001$ for the percentage of time spent on open arms). For the NC-IM groups, the parameter values were significantly attenuated as compared to the IM group, which is consistent with the results of the ANOVA revealing significant interactions between the $\mathrm{NC}$ and IM treatments for each parameter value $(\mathrm{F}(2$, $54)=91.17, \mathrm{P}<0.001$ for the percentage of entries into open arms and $\mathrm{F}(2,54)=18.90, \mathrm{P}<0.001$ for the percentage of time spent on open arms).

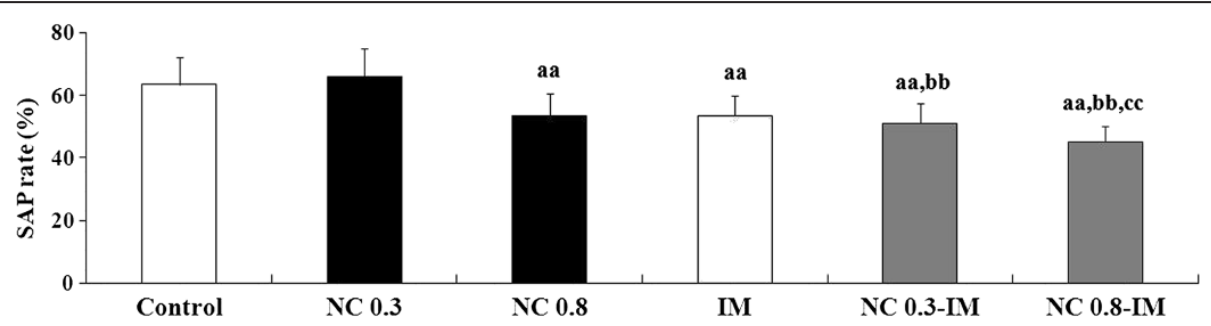

Figure 1 Working memory-related behavioral alterations (SAP rate (\%)) caused by repeated nicotine (NC) and/or immobilization stress (IM) in the Y-maze test. The values at the $2 \mathrm{~h}$ time point after the last NC (0.3 or $0.8 \mathrm{mg} / \mathrm{kg}$, s.c.) or IM treatment are shown as means \pm S.D. ( $n=10$ for each group). aa $(p<0.01)$ : significant attenuation as compared to the control group; bb $(p<0.01)$ : significant attenuation as compared to the NC group; $c c(p<0.01)$ : significant attenuation as compared to the IM group. 


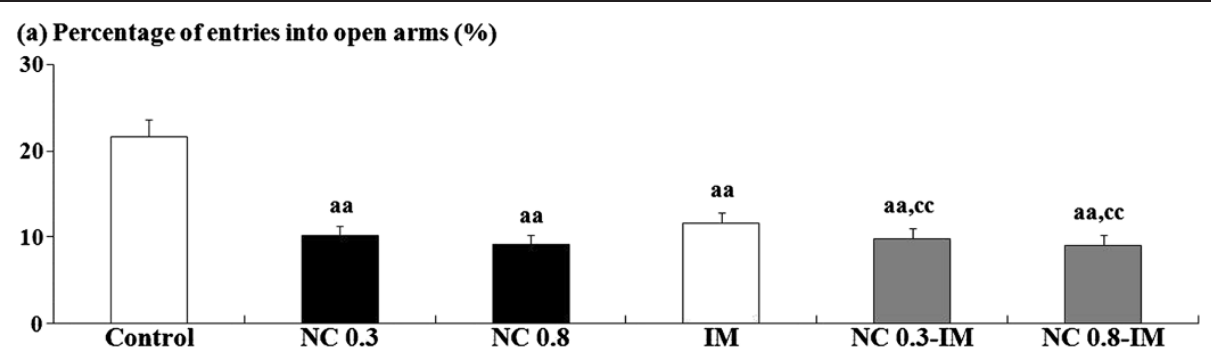

(b) Percentage of time spent on open arms (\%)

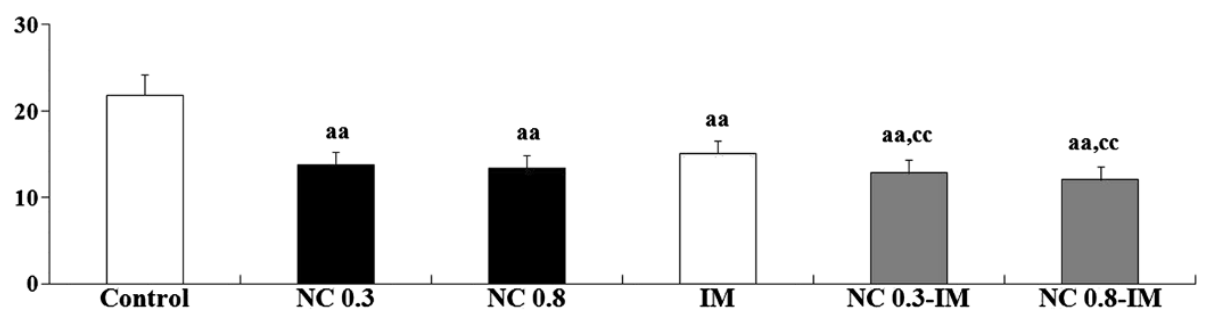

Figure 2 Anxiety-related behavioral alterations caused by repeated nicotine (NC) and/or immobilization stress (IM) in the elevated plus-maze (EPM) test. Data are presented for percentage of entries into open arms (a) and percentage of time spent on open arms (b). The values at the $2 \mathrm{~h}$ time point after the last NC $(0.3$ or $0.8 \mathrm{mg} / \mathrm{kg}$, s.c.) or IM treatment are shown as means \pm S.D. ( $\mathrm{n}=10$ for each group). aa $(p<0.01)$ : significant attenuation as compared to the control group; $c c(p<0.01)$ : significant attenuation as compared to the IM group.

Effects of CB ligands against NC $(0.8 \mathrm{mg} / \mathrm{kg})$ - and/or IMinduced working memory-related behavioral alterations in the Y-maze test

For the $0.8 \mathrm{mg} / \mathrm{kg} \mathrm{NC}$, IM and $0.8 \mathrm{mg} / \mathrm{kg}$ NC-IM groups, at the $2 \mathrm{~h}$ time point, statistically significant recoveries from the impairments in working memory-related behavioral alterations, i.e. recoveries from the attenuated SAP rates, in spite of the absence of significant changes in the total numbers of entries into arms (Table 2), were observed in the groups co-treated with AM (Figure 3a). This is

Table 2 Total number of entries into arms in experiments examining the effects of CB ligands in the Y-maze test (experiments shown in Figure 3 )

\begin{tabular}{ccccc}
\hline (a) AM group & Control & NC & IM & NC-IM \\
\hline Control group & $47.1 \pm 8.3$ & $43.7 \pm 8.5$ & $44.5 \pm 8.2$ & $43.2 \pm 8.6$ \\
AM 0.2 group & $46.9 \pm 8.3$ & $44.0 \pm 8.6$ & $45.1 \pm 8.2$ & $43.7 \pm 8.6$ \\
AM 1 group & $46.6 \pm 8.3$ & $44.5 \pm 8.5$ & $45.5 \pm 8.3$ & $44.1 \pm 8.6$ \\
AM 2.5 group & $46.2 \pm 8.3$ & $45.0 \pm 8.6$ & $46.0 \pm 8.3$ & $44.6 \pm 8.6$ \\
\hline (b) CP group & Control & NC & IM & NC-IM \\
\hline Control group & $47.1 \pm 8.3$ & $43.7 \pm 8.5$ & $44.5 \pm 8.2$ & $43.2 \pm 8.6$ \\
CP 0.5 group & $46.8 \pm 8.3$ & $43.5 \pm 8.6$ & $44.2 \pm 8.4$ & $43.0 \pm 8.7$ \\
CP 2 group & $46.5 \pm 8.4$ & $43.4 \pm 8.6$ & $44.0 \pm 8.5$ & $42.8 \pm 8.8$ \\
CP 5 group & $46.1 \pm 8.4$ & $43.2 \pm 8.7$ & $43.7 \pm 8.5$ & $42.6 \pm 8.9$ \\
\hline (c) VD group & Control & $\mathbf{N C}$ & IM & NC-IM \\
\hline Control group & $47.1 \pm 8.3$ & $43.7 \pm 8.5$ & $44.5 \pm 8.2$ & $43.2 \pm 8.6$ \\
VD 1 group & $46.8 \pm 8.4$ & $43.9 \pm 8.6$ & $44.8 \pm 8.3$ & $43.5 \pm 8.7$ \\
VD 5 group & $46.5 \pm 8.4$ & $44.2 \pm 8.7$ & $45.1 \pm 8.4$ & $43.7 \pm 8.8$ \\
VD 10 group & $46.2 \pm 8.5$ & $44.4 \pm 8.8$ & $45.4 \pm 8.5$ & $43.9 \pm 8.9$ \\
\hline
\end{tabular}

consistent with the results of the ANOVA revealing statistically significant main effects of $\mathrm{AM}(\mathrm{F}(3,144)=$ 11.20, $\mathrm{P}<0.001)$ for the SAP rate. Furthermore, in the groups co-treated with $5 \mathrm{mg} / \mathrm{kg} \mathrm{VD}$, significant recoveries from the behavioral alterations were also observed (Figure 3c), which is consistent with the results of the ANOVA revealing statistically significant main effects of $\operatorname{VD}(F(3,144)=11.74, \mathrm{P}<0.001)$ for the SAP rate. In each $\mathrm{CB}$ ligand-only group, no significant alterations as compared to the control group were observed for each parameter value under the present experimental conditions.

Effects of CB ligands against NC $(0.8 \mathrm{mg} / \mathrm{kg})$ - and/or IMinduced anxiety-related behavioral alterations in the EPM test

For the $0.8 \mathrm{mg} / \mathrm{kg} \mathrm{NC}$, IM and $0.8 \mathrm{mg} / \mathrm{kg}$ NC-IM groups, at the $2 \mathrm{~h}$ time point, statistically significant recoveries from the anxiety-like behavioral alterations, i.e. recoveries from both attenuated percentage of entries into open arms and attenuated percentage of time spent on open arms, in spite of the absence of significant changes in the total numbers of entries into arms (Table 3), were observed in the groups co-treated with VD (1-10 mg/kg) (Figure 4c). This is consistent with the results of the ANOVA revealing statistically significant main effects of VD $(F(3,144)=$ 205.84, $\mathrm{P}<0.001$ for the percentage of entries into open arms and $F(3,144)=58.29, \mathrm{P}<0.001$ for the percentage of time spent on open arms) and significant interactions of the VD versus NC and/or IM treatments $(F(9,144)=18.88$, $\mathrm{P}<0.001$ for the percentage of entries into open arms and $F(9,144)=5.58, P<0.001$ for the percentage of time spent 


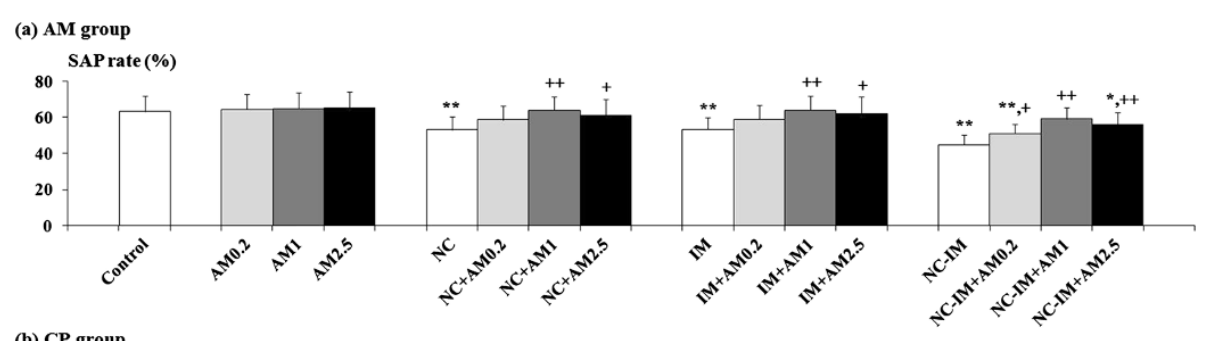

(b) CP group

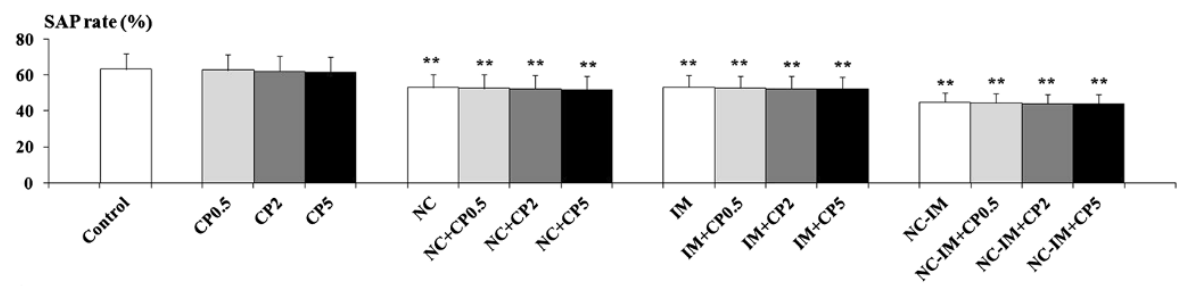

(c) VD group

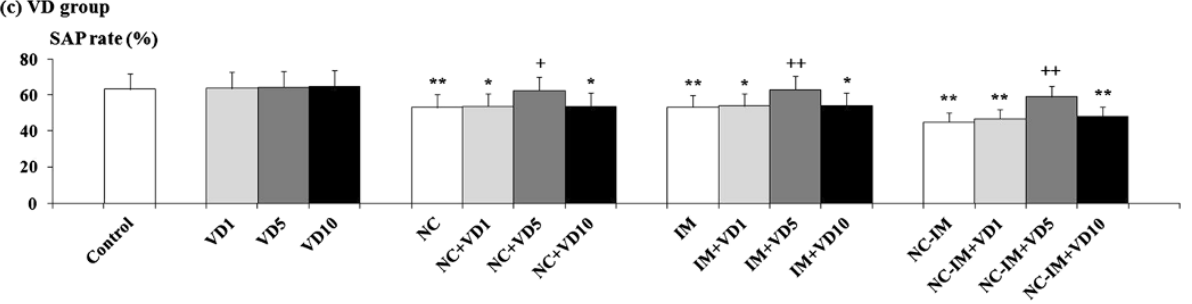

Figure 3 Effects of cannabinoid receptor ligands (CB ligands) on the working memory-related behavioral alterations (SAP rate (\%)) caused by repeated nicotine (NC) and/or immobilization stress (IM) in the Y-maze test. Data of SAP rate are presented for groups of mice co-treated with AM (a), CP (b) and VD (c). The values at the $2 \mathrm{~h}$ time point after the last NC $(0.8 \mathrm{mg} / \mathrm{kg}, \mathrm{s} . \mathrm{c}$.$) or IM treatment are shown as means$ \pm S.D. ( $n=10$ for each group). The abbreviations of the co-administered CB ligands with each i.p. dose $(\mathrm{mg} / \mathrm{kg})$ are noted in the text. The data for the control, NC, IM, and NC plus IM (NC-IM) groups without any CB ligand co-treatments, as well as the CB ligand-only groups, are also shown. * $(p<0.05),{ }^{* *}(p<0.01)$ : significant attenuation as compared to the control group; $+(p<0.05),++(p<0.01)$ : significant increase as compared to the $\mathrm{NC}$, IM, or NC plus IM (NC-IM) group without any CB ligand co-treatments.

Table 3 Total number of entries into arms in experiments examining the effects of CB ligands in the EPM test (experiments shown in Figure 4)

\begin{tabular}{ccccc}
\hline (a) AM group & Control & NC & IM & NC-IM \\
\hline Control group & $63.2 \pm 12.4$ & $58.5 \pm 11.9$ & $60.8 \pm 12.1$ & $55.0 \pm 11.7$ \\
AM 0.2 group & $62.7 \pm 12.6$ & $58.9 \pm 12.0$ & $61.1 \pm 12.3$ & $55.5 \pm 12.1$ \\
AM 1 group & $62.4 \pm 12.9$ & $59.4 \pm 12.2$ & $61.5 \pm 12.4$ & $56.2 \pm 12.4$ \\
AM 2.5 group & $61.9 \pm 13.1$ & $59.9 \pm 12.6$ & $61.7 \pm 12.7$ & $57.5 \pm 12.7$ \\
\hline (b) CP group & Control & NC & IM & NC-IM \\
\hline Control group & $63.2 \pm 12.4$ & $58.5 \pm 11.9$ & $60.8 \pm 12.1$ & $55.0 \pm 11.7$ \\
CP 0.5 group & $62.6 \pm 12.7$ & $58.3 \pm 12.0$ & $60.6 \pm 12.3$ & $54.8 \pm 12.1$ \\
CP 2 group & $62.1 \pm 12.8$ & $58.0 \pm 12.1$ & $60.3 \pm 12.4$ & $54.7 \pm 12.3$ \\
CP 5 group & $61.5 \pm 13.0$ & $57.8 \pm 12.2$ & $60.0 \pm 12.5$ & $54.6 \pm 12.5$ \\
\hline (c) VD group & Control & NC & IM & NC-IM \\
\hline Control group & $63.2 \pm 12.4$ & $58.5 \pm 11.9$ & $60.8 \pm 12.1$ & $55.0 \pm 11.7$ \\
VD 1 group & $62.6 \pm 12.6$ & $58.8 \pm 12.1$ & $61.0 \pm 12.4$ & $54.9 \pm 12.2$ \\
VD 5 group & $62.3 \pm 12.8$ & $59.2 \pm 12.2$ & $61.3 \pm 12.4$ & $55.9 \pm 12.4$ \\
VD 10 group & $61.7 \pm 13.0$ & $59.5 \pm 12.6$ & $61.5 \pm 12.7$ & $56.9 \pm 12.7$ \\
\hline
\end{tabular}

on open arms). Furthermore, in the groups co-treated with $2 \mathrm{mg} / \mathrm{kg} \mathrm{CP}$, significant recoveries in both entries into and time spent on open arms were also observed (Figure $4 \mathrm{~b}$ ), which is consistent with the results of the ANOVA revealing statistically significant main effects of $\mathrm{CP}(\mathrm{F}(3$, $144)=206.08, \mathrm{P}<0.001$ for the percentage of entries into open arms and $\mathrm{F}(3,144)=47.32, \mathrm{P}<0.001$ for the percentage of time spent on open arms) and significant interactions of the $\mathrm{CP}$ versus $\mathrm{NC}$ and/or IM treatments ( $\mathrm{F}$ $(9,144)=20.61, \mathrm{P}<0.001$ for the percentage of entries into open arms and $\mathrm{F}(9,144)=4.50, \mathrm{P}<0.001$ for the percentage of time spent on open arms). In each CB ligand-only group, no significant alterations as compared to the control group were observed for each parameter value under the present experimental conditions.

\section{Discussion}

NC- and/or IM-induced working memory- and anxietyrelated behavioral alterations

In the NC group using repeated treatments of $0.8 \mathrm{mg} / \mathrm{kg}$ $\mathrm{NC}$, as well as in the IM group, behavioral alterations suggestive of working memory impairments were observed in the Y-maze test (attenuated SAP rate) (Figure 1). However, 


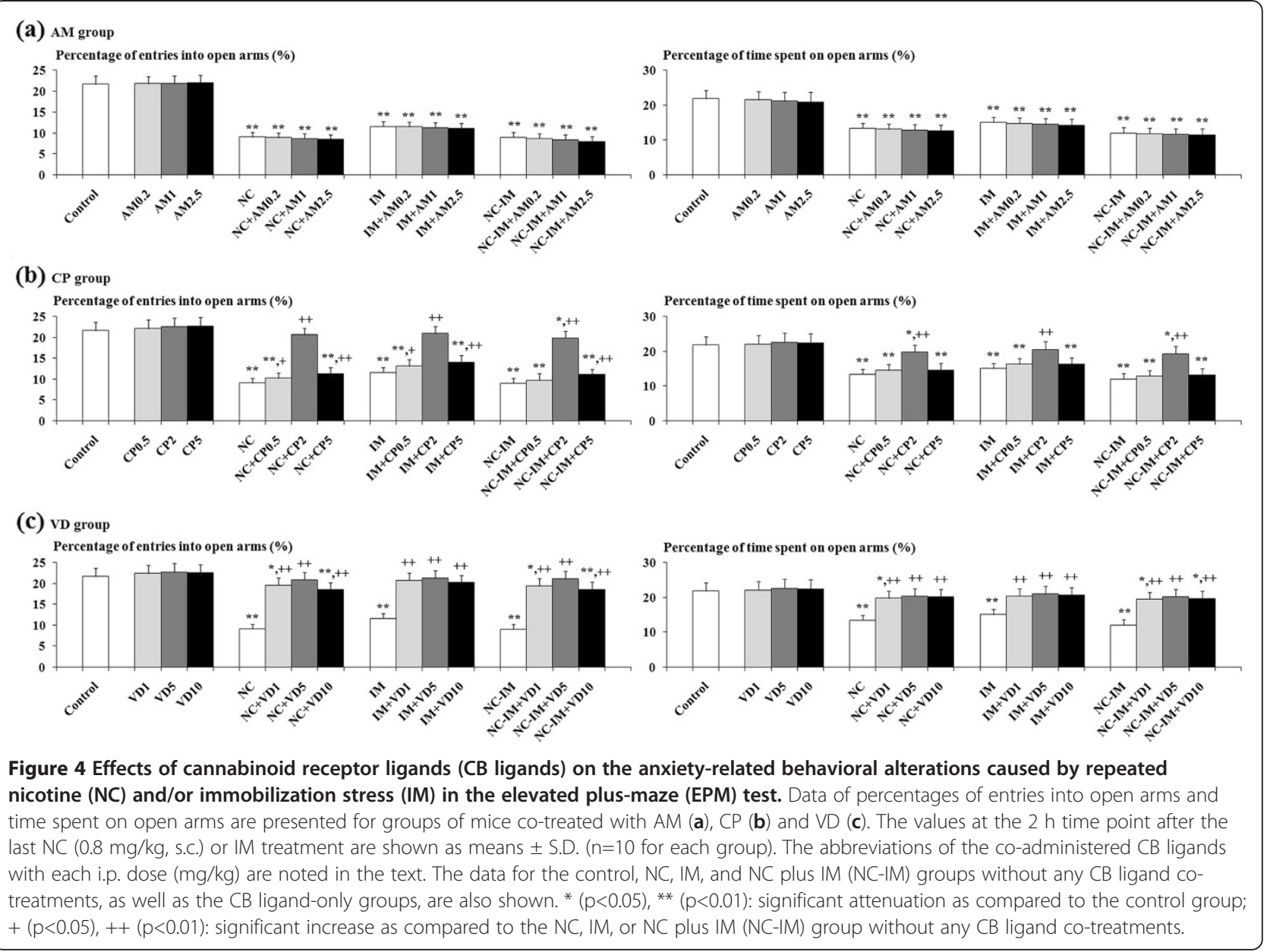

in the NC group using repeated treatments of $0.3 \mathrm{mg} / \mathrm{kg}$ $\mathrm{NC}$, in spite of the appearance of anxiety-like behavioral alterations similar to the IM group (Figure 2), the absence of overt working memory-related behavioral alterations (a slightly increased SAP rate) was observed in the Y-maze test (Figure 1). Previous studies have shown that brain serotonergic and cholinergic systems play crucial roles in mediating anxiety-related behavioral responses [66-68]. In addition to these systems, several neuroendocrine responses (e.g. secretion of corticosterone, norepinephrine, etc.) have been reported to participate in the control of anxiety-like behaviors [69,70]. Similar modifications in these responses were observed between NC and IM [71], and may contribute to their anxiogenic-like effects in the present study (Figure 2). On the other hand, the NC-induced impairments in working memory, unlike the IM-induced impairments, occurred with a limited range of doses (Figure 1). It has been reported that modifications in working memory (both ameliorations and impairments) can occur due to even minuscule changes in prefrontal dopamine (DA) levels [72]. Therefore, the working memory-related behaviors in the $\mathrm{NC}$ groups may be correlated with characteristic but subtle alterations in $\mathrm{nAChR}$-mediated prefrontal DA release, which was controlled by specific nAChR subtypes (e.g. alpha7 nAChRs) [73]. In addition to DA release, the release of other neurotransmitters such as glutamate has been implicated in the $\mathrm{NC}$-induced working memory processes [74].

With respect to the interactions between NC and IM in the NC-IM group, both NC and IM enhanced each other's effects on the working memory- and anxietyrelated behavioral alterations in the Y-maze and EPM tests. Although the relationship between stressors such as IM and NC remains controversial as mentioned above (i.e. "antistress" effects of NC have also been reported depending on the conditions), synergistic effects like those observed in previous studies [34-36] were provided by the NC plus IM treatment in the present experimental model. An augmented increase in secreted hypothalamic-pituitary-adrenal (HPA) hormones and/or immediate early gene expression was demonstrated in those studies $[35,36]$. Furthermore, the involvement of these molecular changes has also been reported for working memory- and anxiety-related behaviors [75-78]. However, further analyses are needed to elucidate the 
mechanisms underlying these complex interactions between NC and IM.

\section{Effects of cannabinoid (CB) ligands}

Consistent with the previous studies described above $[18,43,49,50,52]$, the NC- and/or IM-induced working memory impairment-like behaviors were antagonized by the $\mathrm{CB} 1$ antagonist AM (Figure 3a), and the anxiety-like behaviors were antagonized by the $\mathrm{CB}$ agonist $\mathrm{CP}$ (Figure 4b). Furthermore, VD, a mixed CB1 ligand with partial agonist plus antagonist activities [79], provided recovering effects against the impaired behaviors related to both working memory and anxiety (Figure 3c, 4c). Similarities in some neuronal responses such as prefrontal DA responses have been observed in the immunohistochemical studies between the effects of $\mathrm{NC}$, stressors, and CB1 agonists [21,80-82]. These similarities may result in the $\mathrm{CB} 1$ antagonist-induced recoveries in the working memory-related behavioral alterations. On the other hand, against the NC- and/or IM-induced anxiety-related behavioral alterations, only the CB1 ligands acting at least partially as agonists exerted any anxiolytic-like effects. Although the mechanisms underlying these discrepancies in the effects of $\mathrm{CB}$ ligands have not been elucidated, anxiolytic-like effects of $\mathrm{CB}$ agonists have been shown under several different conditions [83,84]. Furthermore, certain doses of CB1 agonists have been reported to be able to activate the neurotransmission systems related to anti-anxiety (e.g. GABAergic and serotonergic systems) at the molecular level $[53,83,84]$. Therefore, it could be predicted that the antagonistic effects against the anxietylike behaviors were provided at least indirectly by way of agonistic activity on CB1 receptors.

Against both working memory- and anxiety-related behavioral alterations, the CB1 partial agonist/antagonist VD exerted some recovering effects (Figure 3c, 4c). These recovering effects were observed equally in the NC, IM and NC-IM groups. For the behavioral alterations related to working memory impairments, the recovering effects of VD did not exceed those of the $\mathrm{CB} 1$ antagonist $\mathrm{AM}$, which could be predicted considering the partial CB1 agonistic effects of VD. On the other hand, for the behavioral alterations related to anxiety, the recovering effects of VD exceeded those of the $\mathrm{CB}$ agonist $\mathrm{CP}$. These results could not be predicted considering the above-mentioned anxiolytic-like effects of the CB1 agonists without any antagonistic effects. However, contrary to the present results, there are experimental data showing anxiogenic-like or antianxiolytic effects provided by high doses of $\mathrm{CB}$ agonists including $\mathrm{CP}[53,54,85]$. The involvement of an abnormal release of anxiety-related neurotransmitters has been reported for those effects [53,54]. Unlike CP, VD possesses $\mathrm{CB} 1$ antagonistic potential for counteracting anti-anxiolytic effects as an agonist (high doses), and thus may function as an effective anxiolytic-like ligand. Furthermore, recent studies suggest the possibility that CB2 receptors, the $\mathrm{CB}$ receptors initially defined as peripheral receptors, may contribute to anti-anxiolytic effects [86,87]. CB2 receptors are distributed over several regions of the central nervous system [87] and the nonselective $\mathrm{CB}$ agonist $\mathrm{CP}$ seems to provide agonistic effects as well as against $\mathrm{CB} 1$ receptors. With respect to the effects of $A M$ and VD, agonistic effects on the GPR55 receptor subtype, a newly-identified G protein coupled $\mathrm{CB}$ receptor subtype, have also been reported [88-91]. Although the behavioral roles of GPR55 receptors have not been investigated, it is possible that GPR55 distributed in the brain [89] may participate in cognitive processes such as working memory. Furthermore, in vitro studies demonstrated that VD acted as a partial agonist on GPR55 receptors and provided antagonistic effects at high concentrations [91], whereas only full agonistic effects have been reported for AM [88-90]. On the other hand, on CB1 receptors, both VD and $\mathrm{AM}$ provided antagonistic effects at high concentrations $[79,89]$. These characteristic effects of the partial agonist/antagonist VD as a GPR55 antagonist at high concentrations may be correlated with its limited and non-dose-dependent ameliorating effects against working memory impairments, i.e. only $5 \mathrm{mg} / \mathrm{kg} \mathrm{VD}$, but not a lower $(1 \mathrm{mg} / \mathrm{kg})$ or higher $(10$ $\mathrm{mg} / \mathrm{kg}$ ) dose, was effective. In addition to GPR55, the existence of other yet-to-be-cloned $\mathrm{CB}$ receptors has been suggested in memory-related brain regions such as the hippocampus [92]. There may be some contributions of these receptors to the AM- and VDderived attenuating effects against the $\mathrm{NC}$ - and/or IM-induced working memory impairments.

\section{Conclusions}

The present study demonstrated working memory impairment- and anxiety-like behaviors induced by $\mathrm{NC}$, IM and NC-IM treatments in mice. Mutual synergistic effects for NC plus IM were observed for both types of behavioral alterations. In the present study, the involvement of endocannabinoid system was also shown in the processes of working memory and anxiety. However, between the working memory- and anxiety-related behavioral alterations, discrepancies in the types of effective $\mathrm{CB}$ ligands were observed: the CB1 antagonist AM was the most effective against the working memory impairment-related behaviors, whereas the CB1 partial agonist/antagonist VD was the most effective against the anxiety-related behaviors. Since the presence of new CB receptor subtypes such as GPR55 receptors has been clarified recently and the interactions with each CB ligand have been suggested, further research 
into the therapeutic contributions of each $\mathrm{CB}$ receptor subtype is expected.

\section{Competing interests}

The author declares that there are no potential competing interests.

\section{Authors' contributions}

TH designed the study, carried out all experiments and statistical analyses, and prepared the manuscript.

\section{Acknowledgments}

I thank the staffs of Shimizu Laboratory Supplies Co. Ltd. for the technical assistance. I also thank Dr. Yoshiko Yamamoto and Dr. Keiichi Yamamoto, Yamamoto Research Institute of Legal Medicine, for the advice related to the data analysis.

Received: 14 July 2012 Accepted: 31 January 2013 Published: 9 February 2013

\section{References}

1. Zarocostas J: WHO report warns deaths from tobacco could rise beyond eight million a year by 2030. BMJ 2008, 336:299.

2. WHO report on the global tobacco epidemic: 2011 [http://www.who.int/ tobacco/global_report/2011/en/]

3. Heishman SJ: Behavioral and cognitive effects of smoking: relationship to nicotine addiction. Nicotine Tob Res 1999, 1(Suppl 2):143-147.

4. Anstey KJ, von Sanden C, Salim A, O'Kearney R: Smoking as a risk factor for dementia and cognitive decline: a meta-analysis of prospective studies. Am J Epidemiol 2007, 166:367-378.

5. Llewellyn DJ, Lang IA, Langa KM, Naughton F, Matthews FE: Exposure to secondhand smoke and cognitive impairment in non-smokers: national cross sectional study with cotinine measurement. BMJ 2009, 338:b462.

6. Khan ZU, Muly EC: Molecular mechanisms of working memory. Behav Brain Res 2011, 219:329-341.

7. Xu J, Mendrek A, Cohen MS, Monterosso J, Rodriquez P, Simon SL, Brody A, Jarvik M, Domier CP, Olmstead R, Ernst M, London ED: Brain activity in cigarette smokers performing a working memory task: effect of smoking abstinence. Biol Psychiatry 2005, 58:143-150.

8. Malin DH, Goyarzu P: Rodent models of nicotine withdrawal syndrome. Handb Exp Pharmacol 2009, 192:401-434.

9. Park S, Knopick C, McGurk S, Meltzer HY: Nicotine impairs spatial working memory while leaving spatial attention intact. Neuropsychopharmacology 2000, 22:200-209.

10. Jacobsen LK, Krystal JH, Mencl WE, Westerveld M, Frost SJ, Pugh KR: Effects of smoking and smoking abstinence on cognition in adolescent tobacco smokers. Biol Psychiatry 2005, 57:56-66.

11. Swan GE, Lessov-Schlaggar CN: The effects of tobacco smoke and nicotine on cognition and the brain. Neuropsychol Rev 2007, 17:259-273.

12. Toledano A, Alvarez MI, Toledano-Díaz A: Diversity and variability of the effects of nicotine on different cortical regions of the brain - therapeutic and toxicological implications. Cent Nerv Syst Agents Med Chem 2010, 10:180-206.

13. Foulds J, Stapleton J, Swettenham J, Bell N, McSorley K, Russell MA: Cognitive performance effects of subcutaneous nicotine in smokers and never-smokers. Psychopharmacology (Berl) 1996, 127:31-38.

14. Phillips S, Fox P: An investigation into the effects of nicotine gum on short-term memory. Psychopharmacology (Berl) 1998, 140:429-433.

15. Rezvani AH, Levin ED: Cognitive effects of nicotine. Biol Psychiatry 2001, 49:258-267.

16. Ernst M, Heishman SJ, Spurgeon L, London ED: Smoking history and nicotine effects on cognitive performance. Neuropsychopharmacology 2001, 25:313-319.

17. Kleykamp BA, Jennings JM, Blank MD, Eissenberg T: The effects of nicotine on attention and working memory in never-smokers. Psychol Addict Behav 2005, 19:433-438.

18. Balerio GN, Aso E. Maldonado R: Role of the cannabinoid system in the effects induced by nicotine on anxiety-like behaviour in mice. Psychopharmacology (Berl) 2006, 184:504-513.

19. Caldarone BJ, King SL, Picciotto MR: Sex differences in anxiety-like behavior and locomotor activity following chronic nicotine exposure in mice. Neurosci Lett 2008, 439:187-191.
20. Kupferschmidt DA, Funk D, Erb S, Lê AD: Age-related effects of acute nicotine on behavioural and neuronal measures of anxiety. Behav Brain Res 2010, 213:288-292

21. Mizoguchi K, Yuzurihara M, Ishige A, Sasaki H, Chui DH, Tabira T: Chronic stress induces impairment of spatial working memory because of prefrontal dopaminergic dysfunction. J Neurosci 2000, 20:1568-1574.

22. Shansky RM, Rubinow K, Brennan A, Arnsten AF: The effects of sex and hormonal status on restraint-stress-induced working memory impairment. Behav Brain Funct 2006, 2:8.

23. Schoofs $D$, Preuss $D$, Wolf OT: Psychosocial stress induces working memory impairments in an n-back paradigm. Psychoneuroendocrinology 2008, 33:643-653.

24. MacNeil G, Sela Y, Mclntosh J, Zacharko RM: Anxiogenic behavior in the light-dark paradigm follwoing intraventricular administration of cholecystokinin-8S, restraint stress, or uncontrollable footshock in the CD-1 mouse. Pharmacol Biochem Behav 1997, 58:737-746.

25. Chotiwat C, Harris RB: Increased anxiety-like behavior during the poststress period in mice exposed to repeated restraint stress. Horm Behav 2006, 50:489-495.

26. Middleton LS, Cass WA, Dwoskin LP: Nicotinic receptor modulation of dopamine transporter function in rat striatum and medial prefrontal cortex. J Pharmacol Exp Ther 2004, 308:367-377.

27. Singer S, Rossi S, Verzosa S, Hashim A, Lonow R, Cooper T, Sershen H, Lajtha A: Nicotine-induced changes in neurotransmitter levels in brain areas associated with cognitive function. Neurochem Res 2004, 29:1779-1792.

28. Wall PM, Messier C: Concurrent modulation of anxiety and memory. Behav Brain Res 2000, 109:229-241.

29. Clinton SM, Sucharski IL, Finlay JM: Desipramine attenuates working memory impairments induced by partial loss of catecholamines in the rat medial prefrontal cortex. Psychopharmacology (Berl) 2006, 183:404-412.

30. Blanco E, Castilla-Ortega E, Miranda R, Begega A, Aguirre JA, Arias JL, Santín LJ: Effects of medial prefrontal cortex lesions on anxiety-like behaviour in restrained and non-restrained rats. Behav Brain Res 2009, 201:338-342.

31. Goldwater DS, Pavlides C, Hunter RG, Bloss EB, Hof PR, McEwen BS, Morrison $\mathrm{JH}$ : Structural and functional alterations to rat medial prefrontal cortex following chronic restraint stress and recovery. Neuroscience 2009, 164:798-808.

32. Parrott AC: Does cigarette smoking cause stress? Am Psychol 1999, 54:817-820.

33. Parrott AC, Kaye FJ: Daily uplifts, hassles, stresses and cognitive failures: in cigarette smokers, abstaining smokers, and non-smokers. Behav Pharmacol 1999, 10:639-646.

34. Kita T, Okamoto M, Kubo K, Tanaka T, Nakashima T: Enhancement of sensitization to nicotine-induced ambulatory stimulation by psychological stress in rats. Prog Neuropsychopharmacol Biol Psychiatry 1999, 23:893-903.

35. Lutfy K, Brown MC, Nerio N, Aimiuwu O, Tran B, Anghel A, Friedman TC: Repeated stress alters the ability of nicotine to activate the hypothalamic-pituitary-adrenal axis. J Neurochem 2006, 99:1321-1327.

36. Schiltz CA, Kelley AE, Landry CF: Acute stress and nicotine cues interact to unveil locomotor arousal and activity-dependent gene expression in the prefrontal cortex. Biol Psychiatry 2007, 61:127-135

37. Childs E, de Wit H: Hormonal, cardiovascular, and subjective responses to acute stress in smokers. Psychopharmacology (Berl) 2009, 203:1-12.

38. Kotlyar M, Drone D, Thuras P. Hatsukami DK, Brauer L, Adson DE, al'Absi M: Effect of stress and bupropion on craving, withdrawal symptoms, and mood in smokers. Nicotine Tob Res 2011, 13:492-497.

39. Minowa K, Pawlak R, Takada Y, Takada A: Nicotine attenuates stressinduced changes in plasma amino acid concentrations and locomotor activity in rats. Brain Res Bull 2000, 51:83-88.

40. Hsu HR, Chen TY, Chan MH, Chen HH: Acute effects of nicotine on restraint stress-induced anxiety-like behavior, c-Fos expression, and corticosterone release in mice. Eur J Pharmacol 2007, 566:124-131.

41. Andreasen JT, Henningsen K, Bate S, Christiansen S, Wiborg O: Nicotine reverses anhedonic-like response and cognitive impairment in the rat chronic mild stress model of depression: comparison with sertraline. J Psychopharmacol 2011, 25:1134-1141.

42. Aleisa AM, Alzoubi KH, Gerges NZ, Alkadhi KA: Nicotine blocks stressinduced impairment of spatial memory and long-term potentiation of the hippocampal CA1 region. Int I Neuropsychopharmacol 2006, 9:417-426.

43. Hayase T: Chronologically overlapping occurrences of nicotine-induced anxiety- and depression-related behavioral symptoms: effects of anxiolytic and cannabinoid drugs. BMC Neurosci 2007, 8:76. 
44. Hayase T: Depression-related anhedonic behaviors caused by immobilization stress: a comparison with nicotine-induced depressionlike behavioral alterations and effects of nicotine and/or "antidepressant" drugs. J Toxicol Sci 2011, 36:31-41.

45. Riebe CJ, Wotjak CT: Endocannabinoids and stress. Stress 2011, 14:384-397.

46. Castañé A, Valjent $\mathrm{E}$, Ledent C, Parmentier M, Maldonado R, Valverde O: Lack of CB1 cannabinoid receptors modifies nicotine behavioural responses, but not nicotine abstinence. Neuropharmacology 2002, 43:857-867.

47. Picciotto MR, Caldarone BJ, King SL, Zachariou V: Nicotinic receptors in the brain. Links between molecular biology and behavior. Neuropsychopharmacology 2000, 22:451-465.

48. Viveros MP, Marco EM, Llorente R, Lamota L: The role of the hippocampus in mediating emotional responses to nicotine and cannabinoids: a possible neural substrate for functional interactions. Behav Pharmacol 2007, 18:375-389.

49. Riedel G, Davies SN: Cannabinoid function in learning, memory and plasticity. Handb Exp Pharmacol 2005, 168:445-477.

50. Marsicano G, Lafenêtre P: Roles of the endocannabinoid system in learning and memory. Curr Top Behav Neurosci 2009, 1:201-230.

51. Biala G, Kruk M: Cannabinoid receptor ligands suppress memory-related effects of nicotine in the elevated plus maze test in mice. Behav Brain Res 2008, 192:198-202

52. Mateos B, Borcel E, Loriga R, Luesu W, Bini V, Llorente R, Castelli MP, Viveros MP: Adolescent exposure to nicotine and/or the cannabinoid agonist CP 55,940 induces gender-dependent long-lasting memory impairments and changes in brain nicotinic and $\mathrm{CB}(1)$ cannabinoid receptors. J Psychopharmacol 2011, 25:1676-1690.

53. Viveros MP, Marco EM, File SE: Endocannabinoid system and stress and anxiety responses. Pharmacol Biochem Behav 2005, 81:331-342.

54. Moreira FA, Wotjak CT: Cannabinoids and anxiety. Curr Top Behav NeurosCi 2010, 2:429-450

55. Hayase T, Yamamoto Y, Yamamoto K: Stress-related behavioral alterations accompanying cocaine toxicity: the effects of mixed opioid drugs. Nihon Arukoru Yakubutsu lgakkai Zasshi 2000, 35:402-414.

56. Committee on Animal Research of Kyoto University Faculty of Medicine: Guidelines for Animal Experiments of Kyoto University Faculty of Medicine. [http:// www.kyoto-u.ac.jp/uni_int/kitei/reiki_honbun/w002RG00001169.html] (Japanese).

57. Armario A, Gil M, Marti J, Pol O, Balasch J: Influence of various acute stressors on the activity of adult male rats in a holeboard and in the forced swim test. Pharmacol Biochem Behav 1991, 39:373-377.

58. Hayase T: Memory-related and anxiogenic effects of nicotine: roles of cannabinoid receptors. Nihon Arukoru Yakubutsu Igakkai Zasshi 2009, 44:440-441 (Japanese).

59. Yoshida T, Sakane N, Umekawa T, Kondo M: Effect of nicotine on sympathetic nervous system activity of mice subjected to immobilization stress. Physiol Behav 1994, 55:53-57.

60. Sarter M, Bodewitz G, Stephens DN: Attenuation of scopolamine-induced impairment of spontaneous alteration behaviour by antagonist but not inverse agonist and agonist beta-carbolines. Psychopharmacology (Berl) 1988, 94:491-495.

61. Parada-Turska J, Turski WA: Excitatory amino acid antagonists and memory: effect of drugs acting at N-methyl-D-aspartate receptors in learning and memory tasks. Neuropharmacology 1990, 29:1111-1116.

62. Pellow S, Chopin P, File SE, Briley M: Validation of open:closed arm entries in an elevated plus-maze as a measure of anxiety in the rat. J Neurosci Methods 1985, 14:149-167.

63. File SE, Aranko K: Sodium valproate and chlordiazepoxide in the elevated plus-maze test of anxiety in the rat. Neuropsychobiology 1988, 20:82-86.

64. Prior H, Schwegler H, Marashi V, Sachser N: Exploration, emotionality, and hippocampal mossy fibers in nonaggressive $A B / G$ at and congenic highly aggressive mice. Hippocampus 2004, 14:135-140.

65. Alves SH, Pinheiro G, Motta V, Landeira-Fernandez J, Cruz AP: Anxiogenic effects in the rat elevated plus-maze of 5-HT(2C) agonists into ventral but not dorsal hippocampus. Behav Pharmacol 2004, 15:37-43.

66. File SE, Kenny PJ, Cheeta S: The role of the dorsal hippocampal serotonergic and cholinergic systems in the modulation of anxiety. Pharmacol Biochem Behav 2000, 66:65-72.

67. Seth P, Cheeta S, Tucci S, File SE: Nicotinic-serotonergic interactions in brain and behaviour. Pharmacol Biochem Behav 2002, 71:795-805.

68. Hale MW, Shekhar A, Lowry CA: Stress-related serotonergic systems: implications for symptomatology of anxiety and affective disorders. Cell Mol Neurobiol 2012, 32:695-708.
69. Dallman MF, Akana SF, Strack AM, Scribner KS, Pecoraro N, La Fleur SE, Houshyar H, Gomez F: Chronic stress-induced effects of corticosterone on brain: direct and indirect. Ann N Y Acad Sci 2004, 1018:141-150.

70. Morilak DA, Barrera G, Echevarria DJ, Garcia AS, Hernandez A, Ma S, Petre CO: Role of brain norepinephrine in the behavioral response to stress. Prog Neuropsychopharmacol Biol Psychiatry 2005, 29:1214-1224.

71. Morse DE: Neuroendocrine responses to nicotine and stress: enhancement of peripheral stress responses by the administration of nicotine. Psychopharmacology (Berl) 1989, 98:539-543.

72. Cools R, D'Esposito M: Inverted-U-shaped dopamine actions on human working memory and cognitive control. Biol Psychiatry 2011, 69:113-125.

73. Livingstone PD, Srinivasan J, Kew JN, Dawson LA, Gotti C, Moretti M, Shoaib M, Wonnacott S: alpha7 and non-alpha7 nicotinic acetylcholine receptors modulate dopamine release in vitro and in vivo in the rat prefrontal cortex. Eur J Neurosci 2009, 29:539-550.

74. Timofeeva OA, Levin ED: Glutamate and nicotinic receptor interactions in working memory: importance for the cognitive impairment of schizophrenia. Neuroscience 2011, 195:21-36.

75. Issa AM, Rowe W, Gauthier S, Meaney MJ: Hypothalamic-pituitary-adrenal activity in aged, cognitively impaired and cognitively unimpaired rats. J Neurosci 1990, 10:3247-3254.

76. Weiss IC, Pryce CR, Jongen-Rêlo AL, Nanz-Bahr NI, Feldon J: Effect of social isolation on stress-related behavioural and neuroendocrine state in the rat. Behav Brain Res 2004, 152:279-295.

77. Troakes C, Ingram CD: Anxiety behaviour of the male rat on the elevated plus maze: associated regional increase in c-fos mRNA expression and modulation by early maternal separation. Stress 2009, 12:362-369.

78. Matsuo N, Yamasaki N, Ohira K, Takao K, Toyama K, Eguchi M, Yamaguchi S, Miyakawa T: Neural activity changes underlying the working memory deficit in alpha-CaMKII heterozygous knockout mice. Front Behav Neurosci 2009, 3:20.

79. Porter AC, Sauer JM, Knierman MD, Becker GW, Berna MJ, Bao J, Nomikos GG, Carter P, Bymaster FP, Leese AB, Felder CC: Characterization of a novel endocannabinoid, virodhamine, with antagonist activity at the $C B 1$ receptor. J Pharmacol Exp Ther 2002, 301:1020-1024.

80. George TP, Verrico CD, Roth RH: Effects of repeated nicotine pretreatment on mesoprefrontal dopaminergic and behavioral responses to acute footshock stress. Brain Res 1998, 801:36-49.

81. Verrico CD, Jentsch JD, Roth RH: Persistent and anatomically selective reduction in prefrontal cortical dopamine metabolism after repeated, intermittent cannabinoid administration to rats. Synapse 2003, 49:61-66.

82. Viveros MP, Marco EM, File SE: Nicotine and cannabinoids: parallels, contrasts and interactions. Neurosci Biobehav Rev 2006, 30:1161-1181.

83. Braida D, Limonta V, Malabarba L, Zani A, Sala M: 5-HT1A receptors are involved in the anxiolytic effect of Delta9-tetrahydrocannabinol and AM 404, the anandamide transport inhibitor, in Sprague-Dawley rats. Eur J Pharmacol 2007, 555:156-163.

84. Haller J, Mátyás F, Soproni K, Varga B, Barsy B, Németh B, Mikics E, Freund TF, Hájos N: Correlated species differences in the effects of cannabinoid ligands on anxiety and on GABAergic and glutamatergic synaptic transmission. Eur J Neurosci 2007, 25:2445-2456.

85. Genn RF, Tucci S, Marco EM, Viveros MP, File SE: Unconditioned and conditioned anxiogenic effects of the cannabinoid receptor agonist CP 55,940 in the social interaction test. Pharmacol Biochem Behav 2004, 77:567-573.

86. García-Gutiérrez MS, Manzanares J: Overexpression of CB2 cannabinoid receptors decreased vulnerability to anxiety and impaired anxiolytic action of alprazolam in mice. J Psychopharmacol 2011, 25:111-120

87. García-Gutiérrez MS, García-Bueno B, Zoppi S, Leza JC, Manzanares J: Chronic blockade of cannabinoid CB2 receptors induces anxiolytic-like actions associated with alterations in $\mathrm{GABA}(\mathrm{A})$ receptors. $\mathrm{Br} J$ Pharmacol 2012, 165:951-964.

88. Pertwee RG: GPR55: a new member of the cannabinoid receptor clan? $\mathrm{Br}$ J Pharmacol 2007, 152:984-986

89. Ryberg E, Larsson N, Sjögren S, Hjorth S, Hermansson NO, Leonova J, Elebring T, Nilsson K, Drmota T, Greasley PJ: The orphan receptor GPR55 is a novel cannabinoid receptor. Br J Pharmacol 2007, 152:1092-1101.

90. Kapur A, Zhao P, Sharir H, Bai Y, Caron MG, Barak LS, Abood ME: Atypical responsiveness of the orphan receptor GPR55 to cannabinoid ligands. J Biol Chem 2009, 284:29817-29827. 
91. Sharir H, Console-Bram L, Mundy C, Popoff SN, Kapur A, Abood ME: The endocannabinoids anandamide and virodhamine modulate the activity of the candidate cannabinoid receptor GPR55. J Neuroimmune Pharmacol 2012, 7:856-865.

92. de Fonseca FR, Schneider M: The endogenous cannabinoid system and drug addiction: 20 years after the discovery of the CB1 receptor. Addict Biol 2008, 13:143-146.

doi:10.1186/1471-2202-14-20

Cite this article as: Hayase: Working memory- and anxiety-related

behavioral effects of repeated nicotine as a stressor: the role of cannabinoid receptors. BMC Neuroscience 2013 14:20.

\section{Submit your next manuscript to BioMed Central and take full advantage of:}

- Convenient online submission

- Thorough peer review

- No space constraints or color figure charges

- Immediate publication on acceptance

- Inclusion in PubMed, CAS, Scopus and Google Scholar

- Research which is freely available for redistribution 